\title{
Papers
}

\section{Survival of strategic, market defensive, diversified and conservative fund of hedge funds: 1994-2005}

\author{
Greg N. Gregoriou, Maher Kooli*, and Fabrice Douglas Rouah \\ *School of Business and Management, University of Quebec in Montreal (UQAM), \\ P.O. Box 6192, Station 'Centre-ville', Montreal, Quebec, Canada H3C 4R2. \\ Tel: + 1514987 3000, 2082\#,Fax +1 514987 0422, E-mail: kooli.maher@uqam.ca \\ Received (in revised form): 22nd November, 2007
}

Greg N. Gregoriou is Professor of Finance in the School of Business and Economics at State University of New York (Plattsburgh).

Maher Kooli is Professor of Finance at the School of Business and Management, University of Quebec in Montreal (UQAM).

Fabrice Douglas Rouah is Vice President (Senior Quantitative Analyst) for a large financial firm based in Boston, MA.

\section{Practical applications}

This paper helps institutional investors, pension funds and endowments to identify factors driving funds of hedge funds survival. This is important since funds of hedge funds are often perceived as being less risky than individual hedge funds. The study also sheds light on the behaviour of four different funds of hedge funds sub-strategies.

Journal of Derivatives \& Hedge Funds, Vol. 13 No. 4, 2008, pp. 273-286 (C) 2008 Palgrave Macmillan Ltd $1753-9641 \$ 30.00$

\begin{abstract}
In this paper, we investigate the survival lifetimes of fund of hedge funds (FOF) during the January 1994December 2005 period. We focus on four FOF subcategories tracked in the Hedge Fund Research, Inc. database, and find important differences between the sub-categories in the attrition rates of FOFs. More specifically, using Weibull and Cox proportional hazards models, we find that FOF survival times depend on a number of predictor variables, including a FOF's efficiency score from a data envelopment analysis (DEA) model. We also confirm the fact that FOFs are not a homogeneous group of funds, but rather constitute four distinct management styles.
\end{abstract}

Journal of Derivatives \& Hedge Funds (2008) 13, 273-286. doi:10.1057/palgrave.jdhf.1850083

Keywords: fund of hedge funds; survival analysis; Kaplan-Meier; Cox proportional hazards

\section{INTRODUCTION}

The number of hedge funds (HFs) and funds of funds (FOFs) have increased dramatically over the last five years. From the bursting of the Nasdaq bubble in early 2000 to December 2005, the number of HFs increased by almost 
50 per cent. Current estimates of the industry stand at nearly 8,500 funds in existence, managing approximately US $\$ 1.6$ trillion. A large part of this growth is due to FOFs, which are multi-manager HFs. For example, the proportion of FOFs in the TASS/Tremont database has doubled over the last five years. At September 2005, FOFs represented 28 per cent of all HFs in the TASS/Tremont universe. ${ }^{1}$ Yet, the attrition rate of HFs is troubling to investors, as approximately 1,000 HFs disappeared in $2005 .^{2}$ Nevertheless, during the last five years, FOFs have become accepted as proven diversifiers of traditional investment portfolios. If FOFs are to continue to gain acceptance among institutional investors and high networth individuals, precise estimates of their attrition rate and of their expected lifetimes should be made. This is especially important in view of the illiquid nature of these investments, namely the long lock-up periods on capital and infrequent redemption notice periods that these funds often impose on investors.

Although previous studies have estimated the survival times of FOF, the results of those studies are not as robust because they aggregate all FOFs into one class rather than separating them into sub-categories. Many investors believe that all FOFs provide the same benefits, offer the same protection in down markets and under all market conditions. Each FOF sub-strategy, however, has its own purpose in traditional investment portfolios, which would be welcomed by institutional investors. We believe that the four FOF sub-categories behave as different entities from the traditional FOF category, so that an analysis of their life expectancy at the sub-categorical level is warranted.

Further, a number of studies have estimated the survivorship bias in FOFs. Survivorship bias is related, but not identical, to survival analysis. It is important to identify factors driving survival, since those are also the same factors that are responsible for survivorship bias. To the best of our knowledge, no study has attempted to apply survival analysis to the lifetimes of FOFs sub-categories. This is crucial for institutional investors, pension funds and endowments, since FOF are often perceived as being less risky than individual HF. The results of this study lend support to this view, but we find important differences in the risk factors driving survival among the FOF categories, and differences between the yearly attrition rates.

The next section presents the results of previous studies on HF and FOF survival. The subsequent section describes the data and method used in our study. The results of our analyses are presented in the penultimate section before concluding in the final section.

\section{BACKGROUND}

The attrition rate of HFs is usually calculated as the proportion of funds in a sample that dies within a given time period. Most studies have estimated the annual attrition rate of HFs at roughly 5 to 15 per cent, including those of Amin and Kat, ${ }^{2}$ Getmansky et al., ${ }^{3}$ Liang, ${ }^{4}$ Barès et al..$^{5}$ and Rouah. ${ }^{6}$ These estimates vary considerably across time and across HF classifications. In a pioneering paper on HF survival, Brown et al. ${ }^{7}$ estimate the median survival time ${ }^{8}$ of HFs at 30 months. Using TASS data, Amin and $\mathrm{Kat}^{2}$ estimate the median survival time ${ }^{8}$ for HFs to be much longer, approximately five years. Gregoriou, ${ }^{9}$ using ZCM data, and the Securities and Exchange Commission ${ }^{10}$, using Van Hedge data, each estimate it at 5.5 years. Rouah $^{6}$ estimates it at 7.5 years. 
During the 1990-2001 period, Gregoriou' ${ }^{9}$ finds that FOFs have the longest median survival time of all HF classifications, at 7.5 years, and larger FOFs (greater than $\$ 500$ million) survive longer on average. Furthermore, the author concludes that FOFs with annual redemption and low leverage survive the longest. Conversely, FOFs with assets under $\$ 10$ million have the greatest number of dead funds in the Hedge Fund Research (HFR) database during the 1994-2003 period. ${ }^{11}$ In addition, Grecu et al. ${ }^{12}$ observe that FOFs have low hazard rates, the lowest mortality rate and attribute this to the diversification of HF managers in a FOF portfolio. Malkiel and Saha ${ }^{13}$ find an important survivorship bias due to FOFs.

Furthermore, a number of studies have shown that factors such as age, size, leverage, returns and volatility are related to fund survival. Amin and $\mathrm{Kat}^{2}$ and Rouah ${ }^{6}$ find that young funds die faster, whereas Gregoriou ${ }^{11}$ finds that the mean survival time of micro FOFs increases with increasing assets under management (AUM). Gregoriou, ${ }^{9}$ Rouah $^{6}$ and Boyson ${ }^{14}$ observe that small HFs have a higher mortality rate than large ones. Amin and $\mathrm{Kat}^{2}$ further find that size and leverage effect HFs survival and that more than 40 per cent of HFs do not make it past their fifth year, consistent with Liang. ${ }^{4}$ Rouah, ${ }^{6}$ Gregoriou ${ }^{9}$ and Brown et al., ${ }^{7}$ all find that HFs with high returns experience high survival times. Brooks and $\mathrm{Kat}^{15}$ find that approximately 30 per cent of new HFs with poor performance do not live past 36 months. There is also evidence that reputation plays a part in fund survival. According to Jen et al., ${ }^{16}$ poorly performing newly created funds drop out of databases quicker than poorly performing but well-established older funds. Finally, Rouah, ${ }^{6}$ Gregoriou ${ }^{9}$ and Brown et al. ${ }^{7}$ all find that funds with high returns volatility are at increased risk of death.

In this study, we reexamine the attrition rate and survival times of FOFs. More specifically, in our multivariate analyses of survival time we use not only risk factors already considered in the literature but also factors related to fund efficiency and market exposure. Also, since there is ample evidence that HFs are not a homogeneous investment class, we perform our analyses at the sub-categorical FOF level.

\section{DATA AND METHOD}

The data set consists of 1,460 live and 352 dead FOFs reporting monthly returns net of all management and performance fees to the HFR database. We cover the period January 1994 to December 2005, a total of 12 years. To eliminate backfill bias, ${ }^{17}$ we use only FOFs born on or after January 1994. In the HFR database, FOFs enter the database and remain in the 'live' group until they cease reporting their net returns for three consecutive months, at which time they are transferred to the 'dead' group. It is well known indeed that some FOF in the dead group have simply stopped reporting, and are in fact alive and well. ${ }^{4}$ In this study, however, we treat all FOFs in the dead group as having ceased operations, and do not differentiate between FOF that are actually dead, and those that have simply ceased reporting and exited the live group voluntarily.

Owing to the differing nature of the strategies used by the funds they hold, the attrition rate of FOFs could vary by sub-category. For example, we expect FOFs in the Conservative subcategory to experience lower attrition rates than those in the Strategic sub-category. To test this 
Table 1: Definition of the fund of hedge funds sub-categories

Conservative Exhibit one or more of the following characteristics: seeks consistent returns by primarily investing in funds that generally engage in more 'conservative' strategies such as Equity Market Neutral, Fixed Income Arbitrage and Convertible Arbitrage; exhibits a lower historical annual standard deviation than the HFRI Fund of Funds Composite Index. A fund in the HFRI FOF Conservative Index shows generally consistent performance regardless of market conditions.

Diversified Exhibit one or more of the following characteristics: invests in a variety of strategies among multiple managers; historical annual return and/or a standard deviation generally similar to the HFRI Fund of Fund Composite index; demonstrates generally close performance and returns distribution correlation to the HFRI Fund of Fund Composite Index. A fund in the HFRI FOF Diversified Index tends to show minimal loss in down markets while achieving superior returns in up markets.

Market Exhibit one or more of the following characteristics: invests in funds that generally engage in defensive short-biased strategies such as short selling and managed futures; shows a negative correlation to the general market benchmarks (S\&P). A fund in the FOF Market Defensive Index exhibits higher returns during down markets than during up markets.

Strategic Exhibit one or more of the following characteristics: seeks superior returns by primarily investing in funds that generally engage in more opportunistic strategies such as Emerging Markets, Sector specific and Equity Hedge; exhibits a greater dispersion of returns and higher volatility compared to the HFRI Fund of Funds Composite Index. A fund in the HFRI FOF Strategic Index tends to outperform the HFRI Fund of Fund Composite Index in up markets and under-perform the index in down markets.

Source: www.hfr.com.

hypothesis, we calculate yearly attrition rates by separating live and dead funds into one of the four sub-categories defined by HFR. These four sub-categories appear on the HFR, Inc. web-site (www.hfr.com) and are reproduced in Table 1.

Our next analysis is to investigate the impact of different predictor variables on the survival time of FOFs, such as average millions managed, mean average monthly, age, performance fee, leverage, management fee, minimum purchase and redemption period. For each predictor variable, we group FOFs into two groups and calculate the Kaplan-Meier (KM) estimator of the survival function, $\hat{S}(t)$, in each group. The log-rank test is also used to compare the equality of survival functions in each group, and the mean survival time in each group is obtained by integrating over the estimated survival function. Hence, in each group an estimator of the mean survival time is given by

$$
\hat{\mu}=\int_{0}^{\infty} \hat{S}(t) \mathrm{d} t
$$


The second hypothesis we wish to test is that the efficiency of a fund has a positive impact on its survival, even after controlling for other variables known to affect survival. Efficiency can be quantified in terms of a score produced by data envelopment analysis (DEA). ${ }^{4}$

To test this hypothesis, we include in our multivariate survival models a fund's DEA score and we expect a high DEA score to be related with long survival.

FOFs are meant to serve as portfolio diversifiers, and as such, ought to have low correlation to equity indices. Funds with low correlations are those likely to be favoured by investors and rewarded with capital inflows. Consequently, they can be expected to survive longer. To test whether efficient and noncorrelated funds survive longer, we obtain a fund's market beta using a factor model that includes the monthly return on the S\&P 500 index, the Centre for Research in Securities Prices (CRSP) value-weighted index, the Morgan Stanley World Capital Index (MSCI), the Lehmann Brothers Aggregate Bond Index and the Salomon Smith Barney World Government Bond Index. We then include each beta from the regression in the survival model. We expect the parameter estimate to be negative, indicating that funds with a lower market exposure survive the longest.

We investigate the simultaneous effect of the predictor variables on survival time by using a fully parametric Weibull survival regression model. ${ }^{18}$ This model has the following log-linear form for the survival time:

$$
\log (T)=\alpha+X^{\mathrm{T}} \beta+\sigma \varepsilon
$$

where $X$ and $\beta$ denote vectors of predictor variables and parameters, respectively, $\varepsilon$ is an error term, $\alpha$ is an intercept and $\sigma$ is a scale parameter for the error. In this model for $\log (T)$, $\varepsilon$ follows the extreme value distribution, so that $T$ follows a Weibull distribution. When $\sigma=1$, $T$ follows an exponential distribution.

Estimates of $\alpha, \beta$ and $\sigma$ are obtained by maximum likelihood. Note that the expected value of $\varepsilon$ is not zero, and so $\alpha+X_{0}^{\mathrm{T}} \beta$ is not the expected value of $\log (T)$ for a set of values of the predictor variables, $X_{0}$. It is possible, however, to estimate the 50th percentile of $\log (T)$, and of $T$ by exponentiation.

As a robustness check, we also use the Cox proportional hazards $(P H)$ model, which is valid under a far less restrictive set of assumptions. This model assumes that the hazard of any FOF, denoted $\lambda(t, X)$, can be expressed as a product of a baseline hazard $\lambda_{0}(t)$ and a term involving the predictor variables. Usually, this latter term is defined as an exponential term, so that the FOF hazard takes the form

$$
\lambda(t, X)=\lambda_{0}(t) \exp \left(X^{\mathrm{T}} \beta\right)
$$

The Cox PH model does not require that a parametric form for the baseline survival function be specified. It requires only that such a baseline function exist and that the predictive variables act multiplicatively on the baseline hazard.

\section{RESULTS}

Table 2 presents the monthly return statistics of each FOF sub-category during the 1994-2005 period, by survival status (live or dead). It indicates clear differences in the return patterns of these FOFs. The Strategic sub-category has the greatest proportion of dead funds, with approximately 32 per cent of the FOFs classified as dead. This is likely due in part to the 
Table 2: Monthly statistics by sub-category and survival status

\begin{tabular}{lrlllllll}
\hline $\begin{array}{l}\text { FOF sub-category } \\
\text { and status }\end{array}$ & $\begin{array}{l}\text { Number } \\
\text { of funds }\end{array}$ & $\begin{array}{l}\text { Mean } \\
\text { return }(\%)\end{array}$ & $\begin{array}{l}\text { Median } \\
\text { return }(\%)\end{array}$ & $\begin{array}{l}\text { Standard } \\
\text { deviation }(\%)\end{array}$ & Skew & Kurtosis & $\begin{array}{c}\text { Min } \\
(\%)\end{array}$ & $\begin{array}{l}\text { Max } \\
(\%)\end{array}$ \\
\hline Strategic live & 374 & 0.84 & 0.84 & 2.96 & 1.02 & 20.47 & -28.08 & 56.13 \\
Strategic dead & 120 & 0.42 & 0.40 & 5.63 & 0.49 & 11.88 & -43.34 & 71.87 \\
Market defensive live & 59 & 0.71 & 0.61 & 2.60 & 0.31 & 8.48 & -21.4 & 22.49 \\
Market defensive dead & 19 & 0.20 & 0.16 & 2.14 & -0.66 & 9.55 & -17.92 & 13.72 \\
Conservative live & 411 & 0.61 & 0.62 & 1.07 & -0.11 & 10.66 & -11.37 & 13.09 \\
Conservative dead & 64 & 0.49 & 0.48 & 1.28 & -0.03 & 11.60 & -9.78 & 11.05 \\
Diversified live & 616 & 0.70 & 0.69 & 1.67 & 0.36 & 8.40 & -16.94 & 20.35 \\
Diversified dead & 149 & 0.58 & 0.52 & 2.18 & -0.11 & 8.44 & -20.98 & 17.22 \\
All live FOF & 1,460 & 0.71 & 0.68 & 1.98 & 1.04 & 29.95 & -28.08 & 56.13 \\
All dead FOF & 352 & 0.48 & 0.47 & 3.74 & 0.55 & 25.26 & -43.34 & 71.87 \\
& & & & & & & & \\
Total & 1,812 & 0.67 & 0.65 & 2.34 & 0.81 & 39.71 & -43.34 & 71.87 \\
\hline
\end{tabular}

opportunistic strategies that FOF in this subcategory seek out, namely strategies that invest in volatile markets and in emerging markets. The Strategic category has the highest mean monthly standard deviation for both and live funds, but more so for dead funds. As expected, the category with the least amount of volatility is Conservative, which also has the lowest percentage of dead funds of all the FOF subcategories. Skewness and kurtosis are higher for the Strategic classification since this category is susceptible to extreme market events. Also, as expected, live funds have higher returns and lower volatility than dead funds across all sub-categories and at the aggregate level.

Table 3 displays a life table estimate of the four FOF sub-categories. The important feature of this table is the survival column that displays the KM estimates. For example, if we look at the 5-6-year period, the KM estimate for the Conservative category is 0.8536 . Therefore, the estimated probability that a FOF will survive until five or more years is 0.8536 . The hazard, on the other hand, is the instantaneous death rate. The hazard for the conservative category increases from Year 0 (inception) up until Year 2-3 and then starts to decrease again to the end until the 4-5-year interval. After Year 7 until the 12-13-year interval, it is zero, except for the $9-10$-year interval, where it is 0.0533 . The conservative category appears to have the longest survival times (0.749), whereas strategic has the shortest. A possible explanation is that the Strategic FOF category is more focused, with its underlying HF managers specifically concentrating in a particular area with a greater amount of volatility than the remaining categories.

Figure 1 presents a plot of the KM estimator of the survivor function, for each FOF sub-category, and for all FOF aggregated into a single group. It indicates that the Conservative 
Table 3: Life survival and hazard of FOF sub-categories 1994-2005

\begin{tabular}{|c|c|c|c|c|c|c|c|c|}
\hline \multirow[t]{2}{*}{ Lifetime interval } & \multicolumn{2}{|c|}{ Conservative } & \multicolumn{2}{|c|}{ Diversified } & \multicolumn{2}{|c|}{ Market Defensive } & \multicolumn{2}{|l|}{ Strategic } \\
\hline & Survival & Hazard & Survival & Hazard & Survival & Hazard & Survival & Hazard \\
\hline $0-1$ & 1.0000 & 0.0085 & 1.0000 & 0.0122 & 1.0000 & 0.0000 & 1.0000 & 0.0233 \\
\hline $1-2$ & 0.9915 & 0.0334 & 0.9879 & 0.0558 & 1.0000 & 0.0606 & 0.9770 & 0.0516 \\
\hline $2-3$ & 0.9589 & 0.0627 & 0.9343 & 0.0631 & 0.9412 & 0.1333 & 0.9278 & 0.0769 \\
\hline $3-4$ & 0.9006 & 0.0429 & 0.8772 & 0.0782 & 0.8235 & 0.0476 & 0.8591 & 0.0804 \\
\hline $4-5$ & 0.8628 & 0.0107 & 0.8112 & 0.0557 & 0.7852 & 0.1000 & 0.7927 & 0.0982 \\
\hline $5-6$ & 0.8536 & 0.0580 & 0.7673 & 0.1075 & 0.7104 & 0.1053 & 0.7186 & 0.0891 \\
\hline $6-7$ & 0.8055 & 0.0194 & 0.6890 & 0.0519 & 0.6394 & - & 0.6573 & 0.0753 \\
\hline $7-8$ & 0.7901 & - & 0.6541 & 0.0120 & 0.6394 & - & 0.6096 & 0.1250 \\
\hline $8-9$ & 0.7901 & - & 0.6463 & 0.0325 & 0.6394 & - & 0.5379 & 0.0217 \\
\hline $9-10$ & 0.7901 & 0.0533 & 0.6257 & 0.0471 & 0.6394 & - & 0.5263 & 0.0597 \\
\hline $10-11$ & 0.7490 & - & 0.5969 & - & 0.6394 & 0.2857 & 0.4958 & 0.0476 \\
\hline $11-12$ & 0.7490 & - & 0.5969 & - & 0.4795 & - & 0.4727 & - \\
\hline $12-13$ & 0.7490 & - & 0.5969 & - & 0.4795 & - & 0.4727 & - \\
\hline
\end{tabular}

Lifetime interval refers to yearly intervals. Survival represents the life table estimate (in yearly intervals) of the survivor function, or the probability that the event occurs at a time greater than or equal to the start time of each interval. Hazard represents the estimates of the hazard function (or instantaneous death rate) at the midpoint of each yearly interval.

sub-category experiences the longest survival times (top line), while the Strategic sub-category experience the shortest times (bottom line). We also observe that the survival times of all FOF are quite long. We should note, however, that the survival function estimates beyond approximately six years tend to be unreliable, especially for the Conservative and Market Defensive categories. This is could be due to the small number of FOF with long survival times in those two categories.

Table 4 presents the yearly attrition rates of FOF over the 1994-2005 period. These rates are generally lower than those for HFs. Consistent with Figure 1, the Conservative sub-category has the lowest attrition rate, and the Strategic sub-category, the highest. The attrition rates vary across years, but all sub-categories experienced exceptionally high attrition rates during 1998, except for the Market Defensive sub-category. The small number of FOF in that category, however, means that the attrition rate estimates are not reliable. While these attrition rates are consistent with those in the literature, it is worth remembering that these are likely over-estimates because many of the FOF in the dead group are alive and well. These have simply stopped reporting, and should be excluded from the dead group. Indeed, when only liquidated funds are used to define the dead group, the estimates drop by almost one-half. ${ }^{19}$ 


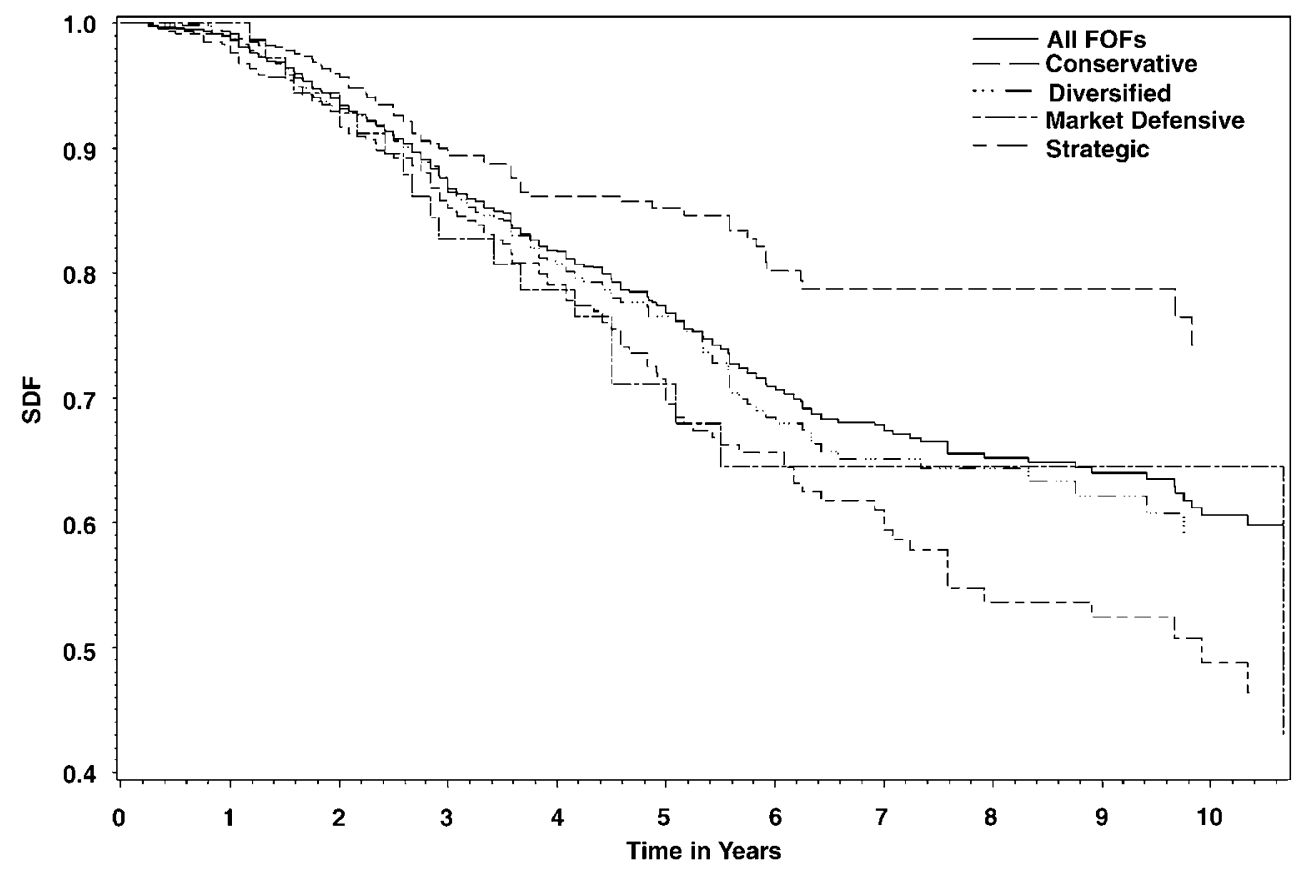

Figure 1: KM Survivor Curve for FOFs, 1994-2005. This figure displays the KM estimate of the survival function of FOF by category. The survival time in years is displayed on the $x$-axis and the corresponding $y$-axis represents the fraction of FOFs surviving. SDF is the Survival distribution function. The survival curve ends at the 12th year because of the right censoring occurring at December 31, 2005.

Table 5 presents an analysis of size and survival, by FOF sub-category. We group funds into quartiles defined by the average AUM of all FOF over their existence. There are $1,812 / 4=453 \mathrm{FOF}$ in each quartile. In each quartile and for each sub-category, we obtain the number of live and dead funds. The results point to a positive relation between survival and AUM, as evidenced by the increasing proportion of live funds in the upper quartiles. In the lowest quartile, 76 per cent of FOF are alive, but in the highest quartile, 93 per cent are alive. This suggests that the relation between size and survival found in previous studies on HFs also exists among FOF. Table 4 also indicates that the Diversified sub-category has the greatest number of funds with ending assets greater than $\$ 83$ million, followed closely by the Conservative sub-category. This can be partly explained by the fact that pension funds and institutional investors, in their efforts to effectively manage downside equity risk, prefer to allocate portions of their investment portfolios to these two categories.

Table 6 reports the mean survival times time ( $\hat{\mu}$ from equation (1)) of FOFs stratified into groups defined by median values of potential predictor variables, along with the standard errors and $p$-values from the log-rank test. The results show differences in the FOF sub-categories, especially when divided by assets and returns. For example, in the Conservative 
sub-category, funds with average assets above the median sub-category survive an average of 9.10 years, while those with average assets below the median survive an average of 5.29 years, a difference that is significant $(p=0.0001)$. The large funds in the other FOF

Table 4: Yearly attrition rates (\%)

\begin{tabular}{cccccc}
\hline Year & Strategic & Diversified & Conservative & $\begin{array}{c}\text { Market } \\
\text { defensive }\end{array}$ & FOF \\
& & & & 12.0 & 3.2 \\
1995 & 3.0 & 2.2 & 2.0 & 6.7 & 4.1 \\
1996 & 3.1 & 6.2 & 0.0 & 7.1 & 6.6 \\
1997 & 7.1 & 8.0 & 3.2 & 0.0 & 9.9 \\
1998 & 11.7 & 9.8 & 10.2 & 2.6 & 2.8 \\
1999 & 4.9 & 1.6 & 2.1 & 5.9 & 8.2 \\
2000 & 8.4 & 10.5 & 5.1 & 1.8 & 4.4 \\
2001 & 7.1 & 5.5 & 1.1 & 0.0 & 1.6 \\
2002 & 2.5 & 2.0 & 0.6 & 6.4 & 3.7 \\
2003 & 4.4 & 4.3 & 1.8 & 7.0 & 5.9 \\
2004 & 8.4 & 5.6 & 4.1 & 10.2 & 5.6 \\
2005 & 5.0 & 5.1 & 6.1 &
\end{tabular}

sub-categories experience similar increases in the mean survival time. FOFs with high returns in the Conservative, Diversified and Strategic categories have a tendency to survive longer than funds with low returns. This is not the case for the Market Defensive category, however, for which funds with low returns survive longer. Recall from Table 1, however, that the sample size in this sub-category is the smallest by far of any category, and so this comparison is likely not tenable.

Table 6 also indicates that only in the Diversified category do funds with no hurdle survive significantly longer (at the 5 per cent level or less) than funds with hurdles. Recall from Table 2 that the returns of these funds show low volatility. One possible explanation for the long survival time of FOF with no hurdle is that FOFs with a low standard deviation may not need to adopt a hurdle to attract investors. The low volatility serves as a strong enough signal that these FOF are competent selectors of HFs. The table also suggests that only in

Table 5: Survival status by average millions managed (AUM)

\begin{tabular}{|c|c|c|c|c|c|c|c|c|c|c|}
\hline \multirow{2}{*}{$\begin{array}{l}\text { Mean AUM } \\
\text { (\$Million) }\end{array}$} & \multicolumn{2}{|c|}{ Strategic } & \multicolumn{2}{|c|}{ Diversified } & \multicolumn{2}{|c|}{ Conservative } & \multicolumn{2}{|c|}{ Market defensive } & \multicolumn{2}{|c|}{ All FOF } \\
\hline & Live & Dead & Live & Dead & Live & Dead & Live & Dead & Live & Dead \\
\hline \multirow[t]{2}{*}{$0-10$} & 110 & 32 & 124 & 52 & 88 & 15 & 22 & 10 & 344 & 109 \\
\hline & $(77 \%)$ & $(23 \%)$ & $(70 \%)$ & $(30 \%)$ & $(85 \%)$ & $(15 \%)$ & $(69 \%)$ & $(31 \%)$ & $(76 \%)$ & $(24 \%)$ \\
\hline \multirow[t]{2}{*}{$10-28$} & 93 & 12 & 178 & 25 & 103 & 21 & 18 & 3 & 392 & 61 \\
\hline & $(89 \%)$ & $(11 \%)$ & $(88 \%)$ & $(12 \%)$ & $(83 \%)$ & $(17 \%)$ & $(86 \%)$ & $(14 \%)$ & $(87 \%)$ & $(13 \%)$ \\
\hline \multirow[t]{2}{*}{$28-83$} & 106 & 70 & 118 & 58 & 72 & 17 & 7 & 5 & 303 & 150 \\
\hline & $(60 \%)$ & $(40 \%)$ & $(67 \%)$ & $(33 \%)$ & $(81 \%)$ & $(19 \%)$ & $(58 \%)$ & $(42 \%)$ & $(67 \%)$ & $(33 \%)$ \\
\hline \multirow[t]{2}{*}{83 or more } & 65 & 6 & 196 & 14 & 148 & 11 & 12 & 1 & 421 & 32 \\
\hline & $(92 \%)$ & $(8 \%)$ & $(93 \%)$ & $(7 \%)$ & $(93 \%)$ & $(7 \%)$ & $(92 \%)$ & $(8 \%)$ & $(93 \%)$ & $(7 \%)$ \\
\hline Total & 374 & 120 & 616 & 149 & 411 & 64 & 59 & 19 & 352 & 1,460 \\
\hline
\end{tabular}


Table 6: Mean survival time and log-rank test

\begin{tabular}{|c|c|c|c|c|c|}
\hline & Conservative & Diversified & Market defensive & Strategic & All FOF \\
\hline High returns & 8.85 & 7.84 & 5.02 & 8.56 & 8.76 \\
\hline Low returns & 7.78 & 7.17 & 6.02 & 6.31 & 7.41 \\
\hline$p$-value & 0.0001 & 0.0002 & 0.0001 & 0.0001 & 0.0001 \\
\hline High volatility & 8.54 & 7.33 & 8.53 & 6.96 & 7.89 \\
\hline Low volatility & 8.33 & 5.58 & 4.42 & 5.60 & 8.21 \\
\hline$p$-value & 0.7665 & 0.0344 & 0.6601 & 0.0003 & 0.0004 \\
\hline High AUM & 9.10 & 6.80 & 9.18 & 8.84 & 8.82 \\
\hline Low AUM & 5.29 & 6.33 & 4.39 & 6.15 & 6.86 \\
\hline$p$-value & 0.0001 & 0.0001 & 0.0221 & 0.0001 & 0.0001 \\
\hline High DEA score & 8.55 & 7.82 & 4.08 & 6.25 & 8.16 \\
\hline Low DEA score & 8.29 & 7.32 & 7.64 & 7.09 & 7.92 \\
\hline$p$-value & 0.6817 & 0.0001 & 0.4652 & 0.0047 & 0.0002 \\
\hline Hurdle & 8.28 & 6.23 & 3.88 & 5.80 & 6.96 \\
\hline No hurdle & 8.52 & 7.94 & 8.38 & 7.68 & 8.50 \\
\hline$p$-value & 0.5805 & 0.0001 & 0.0537 & 0.0724 & 0.0001 \\
\hline High watermark & 5.64 & 7.50 & 7.83 & 7.81 & 8.29 \\
\hline No high watermark & 8.66 & 7.30 & 4.35 & 6.88 & 7.89 \\
\hline$p$-value & 0.6268 & 0.1916 & 0.2278 & 0.1894 & 0.5058 \\
\hline Leverage & 8.11 & 7.65 & 3.83 & 7.17 & 7.83 \\
\hline No leverage & 5.78 & 6.63 & 7.26 & 6.44 & 8.42 \\
\hline$p$-value & 0.0218 & 0.7258 & 0.2416 & 0.0752 & 0.0398 \\
\hline Offshore FOF & 8.38 & 7.82 & 7.76 & 7.49 & 8.30 \\
\hline Onshore FOF & 5.77 & 7.01 & 2.84 & 7.33 & 7.78 \\
\hline$p$-value & 0.1842 & 0.0850 & 0.2359 & 0.8621 & 0.9593 \\
\hline All FOF & 8.25 & 7.48 & 8.15 & 7.33 & 8.28 \\
\hline
\end{tabular}

This table provides the mean survival time and log-rank $p$-value, for different FOF sub-categories. Returns, Volatility, AUM and DEA score are continuous variables. FOF are classified into two groups: those above the median values, and those below. Separate mean survival time estimates are obtained in each group along with the log-rank $p$-value. Hurdle, Highwater Mark, Leverage and Offshore are binary variables. The mean survival time for FOF is obtained in each group, along with the $p$-value. 
the Conservative sub-category is leverage significantly related to survival. Conservative funds using leverage live an average of 8.11 years, while those who do not live an average of 5.78 years. Again, this can possibly be explained by the volatility of these FOF, which is the lowest of any sub-category. The low volatility of these funds means that they have some leeway in their use of leverage. Perhaps their use of leverage is large enough to bolster returns, but modest enough to curtail large fluctuations in returns, thus satisfying risk-averse investors such as pension funds, and helping to preserve the capital base of the FOF.
For each sub-category, we calculate the mean survival time of FOF with DEA efficiency scores below and above the median DEA score of all FOF in the sub-category, and report the results in Table 6. We find that DEA scores in the Strategic classification have an impact on survival, which is the strategy with the highest standard deviation. This can be explained in terms of how the DEA score is obtained. The objective of an input-oriented DEA model is to minimise inputs while maintaining constant outputs. The other three categories have low volatility, and may not have much impact on the inputs since high-volatility funds in the

Table 7: Parameter estimates from the Weibull model

\begin{tabular}{|c|c|c|c|c|c|}
\hline Variable & Conservative & Diversified & Market defensive & Strategic & All FOF \\
\hline Intercept & 0.8632 & $1.9601 \star \star \star$ & -0.5100 & $1.8546 \star \star \star$ & $1.1567 \star \star \star$ \\
\hline DEA score & 2.1769 & 0.2197 & 2.2128 & 0.7223 & $1.0633 \star \star$ \\
\hline No Hurdle & 0.0524 & $0.4850 \star \star \star$ & $0.7951 \star \star$ & $0.4485 \star \star \star$ & $0.3982 \star \star \star$ \\
\hline No HW mark & -0.0675 & 0.2033 & 0.5631 & -0.1320 & 0.0582 \\
\hline No leverage & $0.3398 \star$ & 0.0006 & -0.3030 & 0.2035 & 0.1169 \\
\hline S\&P 500 & -1.6202 & $-1.2979 \star \star$ & 0.9609 & -0.2915 & $-0.5985^{\star \star \star}$ \\
\hline CRSP-VW & -1.5549 & $-1.3489 \star \star \star$ & 1.0072 & $-0.5297 \star \star$ & $-0.7430 \star \star \star$ \\
\hline MSCI World & -1.3445 & -0.0654 & 1.0534 & -0.1617 & -0.2077 \\
\hline LAB & 0.8203 & $0.9113 \star \star \star$ & $1.3482 \star \star \star$ & $0.1014 \star \star$ & $0.0854 \star \star$ \\
\hline SSB & -1.0086 & $1.8802 \star \star \star$ & $1.6110^{\star \star \star}$ & 0.1512 & $0.3447 \star \star \star$ \\
\hline Scale parameter & 0.6930 & 0.6953 & 0.5898 & 0.6532 & 0.6995 \\
\hline Shape parameter & 1.4430 & 1.4383 & 1.6956 & 1.5309 & 1.4295 \\
\hline
\end{tabular}

The DEA score is a continuous variable lying between 0 and 1 . Hurdle is a binary variable taking on the value 1 if a fund has a hurdle rate, and zero otherwise. HW Mark is a binary variable taking on the value 1 if a fund has a highwater mark, and zero otherwise. Leverage is a binary variable taking on the value 1 if a fund uses leverage, and zero otherwise. S\&P500, CRSP-VW, MSCI World, LAB and SSB are the monthly return on the Standard and Poor's 500 Index, the CRSP Value-Weighted Index, the Morgan Stanley Capital International Index, the Lehmann Aggregate Bond Index and the Salomon Smith Barney World Government Bond Index, respectively. The scale and shape parameter are for the Weibull distribution. $\star \star \star, \star \star$, $\star$ denote significance at the $0.01,0.05$, and 0.1 levels respectively. 
Table 8: Hazard ratios from the Cox $\mathrm{PH}$ model

\begin{tabular}{llllll}
\hline Variable & Conservative & Diversified & Market defensive & Strategic & All FOF \\
\hline DEA Score & 0.075 & 0.584 & $0.006 \star \star$ & 0.416 & $0.210 \star \star \star$ \\
No Hurdle & 0.887 & $0.542^{\star \star \star}$ & 0.321 & $0.508 \star \star \star$ & $0.582^{\star \star \star}$ \\
No Leverage & $0.574 \star \star$ & 0.986 & 2.005 & $0.705^{\star}$ & $0.818^{\star}$ \\
No HW Mark & 1.105 & 0.780 & 0.451 & 1.184 & 0.899 \\
S\&P 500 & $29.647 \star$ & $7.598^{\star \star \star}$ & 0.508 & 1.363 & $2.033^{\star \star}$ \\
CRSP-VW & $26.312^{\star}$ & $7.782^{\star \star \star}$ & 0.411 & $1.930^{\star}$ & $2.442^{\star \star \star}$ \\
MSCI World & 12.693 & 1.036 & 0.293 & 1.035 & 0.957 \\
LAB & $0.216^{\star}$ & $0.340 \star \star \star$ & $0.082^{\star \star}$ & $0.769 \star \star \star$ & $0.723 \star \star \star$ \\
SSB & 2.337 & $0.069 \star \star \star$ & $0.043 \star \star \star$ & $0.618^{\star \star}$ & $0.378^{\star \star \star}$ \\
\hline
\end{tabular}

The DEA score is a continuous variable lying between 0 and 1 . Hurdle is a binary variable taking on the value 1 if a fund has a hurdle rate, and zero otherwise. HW Mark is a binary variable taking on the value 1 if a fund has a highwater mark, and zero otherwise. Leverage is a binary variable taking on the value 1 if a fund uses leverage, and zero otherwise. S\&P500, CRSP-VW, MSCI World, LAB and SSB are the monthly returns on the Standard and Poor's 500 Index, the CRSP Value-Weighted Index, the Morgan Stanley Capital International Index, the Lehmann Aggregate Bond Index and the Salomon Smith Barney World Government Bond Index, respectively. $\star \star \star, \star \star, \star$ denote significance at the $0.01,0.05$, and 0.1 levels respectively.

Strategic category are better at controlling inputs, whereas low-volatility funds may not require precise control of inputs. Although the mean survival times of each category are close, the Conservative has the longest survival time (8.25 years) and as expected the Strategic sub-category has the lowest ( 7.33 years).

Note that in Table 6 the median survival time is not reported, because only funds born in January 1994 or later are used for analysis, and so the follow-up time is not sufficiently long to observe one-half of the funds dying. This implies that the survival curves in Figure 1 do not cross the $y$-axis at the 0.50 probability point (except for the Strategic sub-category), which implies that the median survival times are likely longer than the 12-year time period under consideration. In Table 2, the mean survival time $(\mu)$ is estimated at 8.28 years. We should note, however, that Table 2 estimates are downward biased because in all cases the largest survival time is censored.

Rather than examining the effects of predictor variables on survival individually, it is preferable to examine the joint effect of these variables simultaneously, since some variables significant related to survival could become insignificant once other variables are controlled for. Table 7 presents parameter estimates $(\hat{\beta}$ in equation (2)) from the Weibull model, for all sub-categories and for all FOF aggregated. The results are consistent with those of Table 6 , since in the Weibull model $\hat{\beta}>0$ increases survival, while $\hat{\beta}<0$ decreases survival. Specifically, we find that the survival time increases for FOF with a high DEA score and no hurdle rate. The DEA score, however, is significant only at the aggregate level. We also find that, in general, 
FOF with high exposure to equity indices (S\&P500 and CRSP-VW) tend to experience shorter lifetimes, while the opposite is true for FOF with exposure to bond indices (LAB and SSB). In this model, the predictor variables act multiplicatively on $T$, and so their effect on survival can be quantified. In the model for all FOF, for example, the coefficient for no hurdle is 0.3982 and significant at the 1 per cent level. Since $\exp (0.3982) \approx 1.49$, this indicates that FOF with no hurdle live roughly 49 per cent longer than FOF with a hurdle. Similarly, the coefficient for DEA (1.0633) implies that every 10 per cent increase in the DEA score increases survival by 11.2 per cent. $^{20}$

Finally, the confidence intervals for the scale parameter $(\sigma)$ do not include one (intervals not shown). Thus, the Weibull distribution better describes the FOF survival times than the exponential distribution.

As a robustness check, we also run the Cox $\mathrm{PH}$ model on the lifetimes of FOFs in each sub-category. Table 8 presents estimates of hazard ratios $(H R)$ from this model, obtained as $H R=\exp (\hat{\beta})$, where $\hat{\beta}$ is from equation (3). In this model, $H R<1$ decreases the hazard (increases survival), while the opposite is true for $H R>1$. Overall, the results are consistent with those of the Weibull model. For example, HR is less than one for DEA score, bond indices and no hurdle, but $H R$ is greater than one for equity indices. The effects of these variables can only be quantified in terms of the hazard function, as $(H R-1) \times 100$ per cent, not in terms of survival time. For example, $H R=0.582$ for no hurdle among all FOF implies that FOF with no hurdle rate have a decrease in hazard of roughly 42 per cent relative to those with a hurdle rate.

\section{CONCLUSION}

In this paper, we examine the survival and attrition of four FOFs sub-categories over a 12year time period. Not surprisingly, we find that live FOF outperform dead ones, even though some FOF in the dead group are alive and well. We also find the attrition rates of FOF over the 1994-2005 time period to be lower than that of individual HF, except in 1998, when many funds died off and few were created. By FOF sub-categories, we find that the Conservative sub-category suffered the lowest attrition and the size to be strongly related to survival status, with small funds suffering the highest attrition. FOFs that are not constrained by a hurdle rate survive longer, perhaps because the absence of a hurdle rate implies that these FOFs conserve more of the profits they generate.

In univariate analyses of mean survival, we find a weak effect of DEA score on survival. The effect of DEA score in our multivariate models, however, is stronger and points to increased survival for efficient FOFs. We also find that FOF with high exposure to bond indices, but low exposure to equity indices, survive longer, especially for the Market Defensive and Diversified sub-categories. These results suggest that strategies used by FOF could revolve around bonds, and that some FOFs could invest in HF that are heavily exposed to bonds or to structured products built around bonds, such as Collateralised debt obligations.

\section{References and Notes}

1 Brown, S.J. (2006) 'Fund of Hedge Funds', in Gregoriou, G.N. (ed.), Elsevier-ButterworthHeinemann, Burlington, MA.

2 Amin, G.S. and Kat, H.M. (2003) 'Welcome to the Dark Side: Hedge Fund Attrition and Survivorship Bias Over the Period 1994-2001', Journal of Alternative Investments, Vol. 6, No. 1, pp. 57-73. 
3 Getmansky, M., Lo, A. and Mei, S. (2004) 'Sifting Through the Wreckage: Lessons from Recent Hedge-Fund Liquidations', Journal of Investment Management, Vol. 2, No. 4, pp. 6-38.

4 Liang, B. (2000) 'Hedge Funds: The Living and the Dead', Journal of Financial and Quantitative Analysis, Vol. 35, No. 3, pp. 309-326.

5 Barès, P.A., Gibson, R. and Gyger, S. (2001) 'Style Consistency and Survival Probability in the Hedge Fund Industry', Working Paper, Swiss Federal Institute of Technology Lausanne EPFL and University of Zurich.

6 Rouah, F. (2006) 'Competing Risks in Hedge Fund Lifetimes', Working Paper, McGill University, Montreal, Canada.

7 Brown, S.J., Goetzmann, W.N. and Park, J. (2001) 'Careers and Survival: Competition and Risk in the Hedge Fund and CTA Industry', Journal of Finance, Vol. 65, No. 5, pp. 1869-1886.

8 The median survival time is defined as the age at which one half of the funds in the sample die.

9 Gregoriou, G.N. (2002) 'Hedge Fund Survival Lifetimes', Journal of Asset Management, Vol. 2, No. 3, pp. 237-252.

10 Securities and Exchnage Commission (2003) 'Implications of Growth of Hedge Funds', Staff Report to the United States Securities and Exchange Commission, Washington, D.C.

11 Gregoriou, G.N. (2006) 'Micro Survival of Hedge Funds', Derivatives Use, Trading and Regulation, Vol. 12, No. 3, pp. 209-218.
12 Grecu, A., Malkiel, B.G. and Saha, A. (2006) 'Why Do Hedge Funds Stop Reporting Their Performance?', Working Paper CEPS No. 124, Princeton University, Princeton, NJ.

13 Malkiel, B.G. and Saha, A. (2004) 'Hedge Funds: Risk and Return', Working Paper CEPS No. 104, Princeton University, Princeton, NJ.

14 Boyson, N. (2002) 'How Are Hedge Fund Manager Characteristics Related to Performance, Volatility and Survival', Working Paper, Ohio State University, Columbus, OH.

15 Brooks, C. and Kat, H. (2001) 'The Statistical Properties of Hedge Fund Index Returns and Their Implications for Investors', Working Paper, University of Reading ISMA Centre, Reading, UK.

16 Jen, P., Heasman, C. and Boyatt, K. (2001) 'Alternative Set Strategies: Early Performance in Hedge Fund Managers', Internal Document, Lazard Asset Management, London, UK.

17 Fung, W. and Hsieh, D.A. (2000) 'Performance Characteristics of Hedge Funds and Commodity Funds: Natural vs. Spurious Biases', Journal of Financial and Quantitative Analysis, Vol. 35, No. 3, pp. 291-307.

18 Kalbflesich, J.D. and Prentice, R.L. (2002) 'The Statistical Analysis of Failure Time Data', John Wiley \& Sons, Hoboken, NJ.

19 Results are not shown but available from the authors.

20 Calculated as $[\exp (1.0633 \times 0.1)-1] \times 100 \%$. 